OPEN ACCESS

Edited by:

Mingxiang Xiong,

Guangzhou University, China

Reviewed by:

Hongjian Du,

National University of Singapore,

Singapore

Tianyi Song,

Beijing University of Technology,

China

*Correspondence:

Zongping Chen

zpchen@gxu.edu.cn

Chunheng Zhou

chzhou2014@hotmail.com

Specialty section:

This article was submitted to

Structural Materials,

a section of the journal

Frontiers in Materials

Received: 30 September 2020

Accepted: 30 October 2020

Published: 16 December 2020

Citation:

Xu D, Chen Z and Zhou C (2020)

Seismic Performance of Recycled

Concrete Filled Circular

Steel Tube Columns.

Front. Mater. 7:612059.

doi: 10.3389/fmats.2020.612059

\section{Seismic Performance of Recycled Concrete Filled Circular Steel Tube Columns}

\author{
Dingyi $\mathrm{Xu}^{1}$, Zongping Chen ${ }^{2,3 *}$ and Chunheng Zhou ${ }^{4 *}$ \\ ${ }^{1}$ The First People's Hospital of Lianyungang, Lianyungang, China, ${ }^{2}$ College of Civil Engineering and Architecture, Guangxi \\ University, Nanning, China, ${ }^{3}$ Guangxi Key Laboratory of Disaster Prevention and Engineering Safety, Guangxi University, Nanning, \\ China, ${ }^{4}$ School of Civil and Environmental Engineering, Ningbo University, Ningbo, China
}

This study was conducted to experimentally investigate the behavior of recycled concretefilled circular steel tube (RCFST) columns subjected to cyclic loading. Ten specimens were prepared and tested. Four parameters were used to characterize seismic behavior: the replacement percentage of recycled coarse aggregate, slenderness ratio, axial compression level, and steel ratio. A novel calculation method for the bearing capacity for RCFST columns is established. The failure processes and modes of RCFST columns are found to be similar to normal concrete-filled steel tube columns. Varying the replacement percentage of recycled coarse aggregate has little effect on the hysteresis curves of the RCFST columns. The RCFST columns also show seismic performance similar to that of concrete-filled steel tubes. The displacement ductility of all specimens is larger than 3.0 and the equivalent viscous damping coefficients corresponding to the ultimate load range from 0.305 to 0.460 .

\begin{abstract}
Keywords: seismic performance, replacement percentage, column, recycled concrete filled circular steel tube, recycled concrete
\end{abstract}

\section{INTRODUCTION}

The rapid and extensive development of construction projects across the globe accompanying urbanization and modern economic advancement has resulted in massive amounts of waste. The management of construction waste has become an important issue. The traditional landfill approach not only occupies valuable land resources, but also destroys local environments. The recycling or reuse of waste concrete can effectively mitigate this problem and has attracted a great deal of scholarly attention accordingly.

Recycled concrete (RC), usually called recycled aggregate concrete, is a coarse aggregate material composed partially or completely from crushed waste concrete as a replacement for the nature coarse aggregate. The mechanical properties of RC have been extensively studied over the years. The presence of attached old cement mortar in recycled coarse aggregate (RCA) materials, which increases, naturally, as the RCA replacement percentage increases, gradually deteriorates the properties of RC. Compared to conventional nature aggregate concrete, RC has lower strength and elastic modulus (Amnon, 2003; Xiao et al., 2012b), higher shrinkage and creep (Hansen and Boegh, 1985; Etxeberria et al., 2007), and lower durability (de Brito et al., 2016).

RC-filled circular steel tubes (RCFSTs), also called recycled aggregate concrete filled steel tubes, are materials in which natural aggregates are partly or entirely substituted with RC. Experimental research on RCFST columns has shown significant achievements, particularly in the axial compressive performance of RCFSTs. Wu et al. (2011) tested CFST stub columns filled with 
demolished concrete lumps or segments; Mohanraj et al. (2011) investigated the behavior of circular and square RCFSTs. Xiao et al. (2012a) conducted axial compression tests on RCFST and RC materials confined by glass fiber reinforced plastic tubes. Liu et al. (2012) developed a new damage model and idealized the RC and ordinary concrete as a shunt-wound and series-wound spring. Tam et al. (2014) investigated the behavior of RC-filled stainless steel stub columns. Huang et al. (2015) developed a mechanical model for analyzing the behavior of axially loaded RCFST stub columns. Wang et al. (2015) studied the compressive behavior of normal-strength RCFST stub columns under axial loading. Shi et al. (2015) tested two section sizes of square hollow sections filled with geopolymeric RC (GRC) and RC, respectively. Niu and Cao (2015) reported the damage development and failure mode in RCFST columns.

Dong et al. (2016) experimentally and theoretically investigated the influence of different parameters on RCFST and CFST columns. They found that the damage development and failure mode of RCFST columns are similar to those of CFST columns. Steel tube confinement was also shown to improve the mechanical behavior of RC effectively; the RCA replacement percentage slightly altered the response of the core concrete. The ultimate load of RCFST columns was higher than that of the conventional CFST columns as well, and the replacement of NC with RC had relatively little influence on the axial compressive behavior of square section specimens compared to circular specimens. The load-carrying capacity of the circular RCFST was higher than that of square section tubes. Other studies have provided valuable information regarding the effects of eccentric loading performance (Yang and Han, 2006b), long-term sustained loading behavior (Yang and Han, 2006a; Yang et al., 2008; Yang, 2011; Geng et al., 2015), and design calculations (Yang and Hou, 2015) in RCFST and CFST columns.

Despite these valuable contributions to the literature, there have been relatively few studies on the seismic behavior of RCFST columns. Yang et al. (2009) and Yang and Zhu (2009) explored the experimental performance of RCFST columns with different concrete types and axial load ratios subjected to cyclic lateral loading; they performed similarly to normal CFST columns and showed high ductility and energy dissipation abilities. Wu et al. (2013) investigated the seismic performance of thin-walled circular steel tubular columns filled with combinations of demolished concrete blocks and fresh concrete (FC) to find that they have similar seismic performance as reference columns filled with FC alone; the lateral strength of columns filled with demolished concrete blocks/FC were slightly lower than that of the FC-filled reference column. Xiao et al. (2014) conducted seismic tests on RCFST and RC-filled glass fiber reinforced plastic tube (RCFF) columns, where both the deformation and bearing capacities of RCFF and RCFST columns markedly improved while the seismic behavior of RCFST columns was better than that of RCFF columns. Yang et al. (2015) reported that square RCFST specimens have nearly equivalent lateral impact resistance to their normal CFST counterparts.

Previous studies have mainly centered on RCFST axial and eccentric loading performance. There have been relatively few studies on the seismic performance of these materials. There has been one previous investigation targeting the seismic performance of circular RCFST columns with different concrete types and axial load levels. However, as the key factors, the effects of RCA replacement percentage, slenderness ratio, or steel ratio on the seismic behavior of RCFST columns were worthy of further study.

Therefore, to analyzed the effect of the above mentioned parameters on the seismic performance of RCFST column. A test program was developed in this study to investigate the seismic performance of circular RCFSTs under low cycled reversed loading. This work contributes workable guidelines for the design and application of seismic-resistant RCFST structures. The RCA replacement percentage, slenderness ratio, axial compression level, and steel ratio were tested in 10 circular RCFST columns to investigate the effects of these four parameters on seismic performance. Several theories are drawn based on the results, then utilized to calculate the compression-bending capacity of the specimens.

\section{EXPERIMENTAL PROGRAM}

\section{Specimen Design}

Ten specimens were fabricated for this experiment. Their respective elevations are shown in Figure 1. The design parameters, including $\gamma, \lambda, n$, and $\alpha$, are listed in Table 1. A straight seam circular steel tube and typical ordinary Portland cement $(\mathrm{C})$ with a 28 days nominal compression strength of $42.5 \mathrm{MPa}$ were used in addition to river sand $(\mathrm{S})$, urban water $(\mathrm{W})$, natural coarse aggregate (NCA), and RCA. RCA and NCA are continuous gradations of rubble with maximum diameter of $20 \mathrm{~mm}$. The bulk density of RCA and NCA are 1,270 and $1,435 \mathrm{~kg} / \mathrm{m}^{3}$, respectively. The apparent density of RCA and NCA are 2,655 and $2,722 \mathrm{~kg} / \mathrm{m}^{3}$, respectively. The RCA replacement percentage, namely, the percentage of the RCA mass to the mass of all the coarse aggregates in the concrete, was considered as an important parameter. All the concrete of specimens' base was NCA. The RC strength grade used in this study is $\mathrm{C} 40$ and the mix proportions of RC by sample are listed in Table 2 .

\section{Mechanical Properties of Materials}

Three tensile test specimens were prepared according to the Chinese standard Metallic materials: tensile testing at ambient temperature (Chinese GB Standards, 2002). Three standard cubes and prism blocks were cast and cured under same natural conditions according to the Chinese standard Standard for test method of mechanical properties on ordinary concrete (National Standards of the People's Republic of China, 2003). Their measured mechanical properties are shown in Tables 3-5.

As shown in Tables 4,5, the $f_{\text {cu }}$ and $f_{\mathrm{c}}$ of RC are similar under different replacement percentages. The amplitudes of $f_{\mathrm{cu}}$ variation are $8.55,5.91$, and $-6.88 \%$, respectively, while the amplitudes of $f_{c}$ variation are $-0.54,3.52$, and $-3.66 \%$, respectively - all are within the permissible error range for engineering, indicating that the replacement percentage does not impact the strength of RC. The Poisson's ratios of RC gradually increase as the stress level 


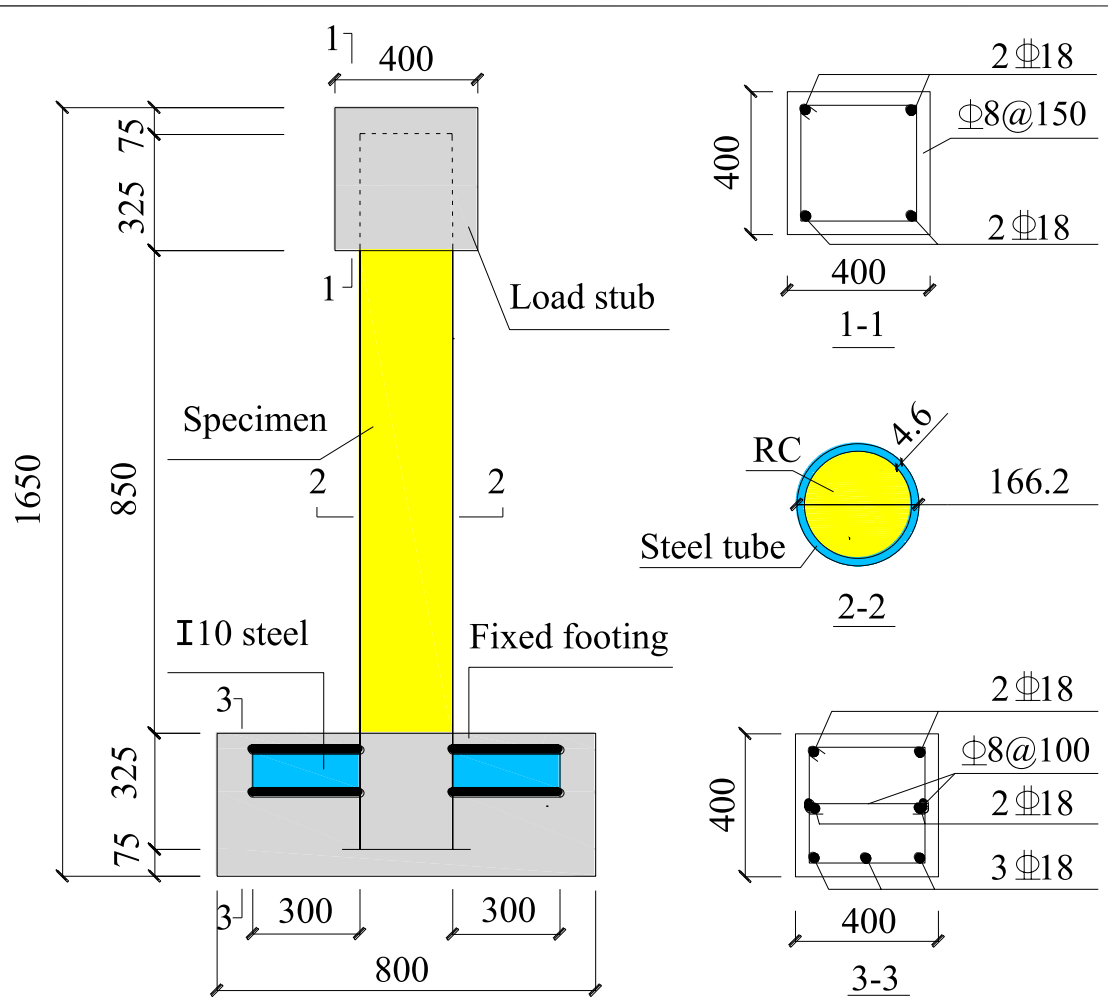

FIGURE 1 | Elevation of specimens.

TABLE 1 | Design parameters of specimens.

\begin{tabular}{|c|c|c|c|c|c|c|c|c|c|c|}
\hline $\begin{array}{l}\text { Specimen } \\
\text { No. }\end{array}$ & C-1 & C-2 & C-3 & C-4 & C-5 & C-6 & C-7 & C-8 & C-9 & C-10 \\
\hline$\gamma(\%)$ & 0 & 30 & 70 & 100 & 100 & 100 & 100 & 100 & 100 & 100 \\
\hline$\lambda$ & 20.46 & 20.46 & 20.46 & 20.46 & 18.05 & 15.64 & 20.67 & 20.67 & 20.67 & 20.67 \\
\hline$n$ & 0.34 & 0.34 & 0.35 & 0.34 & 0.34 & 0.34 & 0.47 & 0.41 & 0.35 & 0.29 \\
\hline$\alpha$ & 0.12 & 0.12 & 0.12 & 0.12 & 0.12 & 0.12 & 0.07 & 0.07 & 0.07 & 0.07 \\
\hline$\theta$ & 1.35 & 1.36 & 1.31 & 1.36 & 1.36 & 1.36 & 0.70 & 0.70 & 0.70 & 0.70 \\
\hline
\end{tabular}

TABLE 2 | Mix proportions of RC.

\begin{tabular}{lccccccc}
$\boldsymbol{\gamma}(\%)$ & $\mathbf{W} / \mathbf{C}$ & $\begin{array}{c}\text { Sand ratio } \\
\text { (\%) }\end{array}$ & $\mathbf{W}(\mathbf{k g})$ & $\mathbf{C ~ ( k g )}$ & $\mathbf{S}(\mathbf{k g})$ & $\mathbf{N C A}(\mathbf{k g})$ & $\mathbf{R C A ~ ( k g ) ~}$ \\
\hline 0 & 0.47 & 33.6 & 204.8 & 435.7 & 564.3 & $1,115.2$ & 0.0 \\
30 & 0.47 & 33.6 & 204.8 & 435.7 & 564.3 & 780.6 & 334.6 \\
70 & 0.47 & 33.6 & 204.8 & 435.7 & 564.3 & 334.6 & 780.6 \\
100 & 0.47 & 33.6 & 204.8 & 435.7 & 564.3 & 0.0 & $1,115.2$
\end{tabular}

TABLE 3 | Measured mechanical properties of steel tube.

\begin{tabular}{lccccc}
\hline $\begin{array}{l}\text { Steel tube } \\
\text { wall thickness } \\
(\mathbf{m m})\end{array}$ & $\boldsymbol{f}_{\mathbf{y}} / \mathbf{M P a}$ & $\boldsymbol{f}_{\mathbf{u}} / \mathbf{M P a}$ & $\boldsymbol{E}_{\mathbf{s}} / \times \mathbf{1 0}^{\mathbf{5}} \mathbf{M P a}$ & $\boldsymbol{v}_{\mathbf{s}}$ & $\begin{array}{c}\boldsymbol{\varepsilon}_{\mathbf{y}} \\
\left.\boldsymbol{\varepsilon}_{\boldsymbol{\mu}}\right)\end{array}$ \\
\hline 4.6 & & & & & \\
\hline 2.7 & 416.0 & 489.4 & 2.08 & 0.296 & 2,000 \\
& 366.8 & 431.6 & 1.98 & 0.257 & 1,853
\end{tabular}

increases, but do not markedly change as the replacement percentage changes. This suggests that the lateral deformation performance of RC is not altered by increasing replacement percentage. The elasticity modulus amplitudes of variation of $\mathrm{RC}$ under different replacement percentages are $3.23,1.30$, and $-5.66 \%$. At the material level, the replacement percentage appears to have little influence on the mechanical properties of RC. Even a $100 \%$ replacement percentage did not appear to weaken the strength or deformation performance of RC.

\section{Loading and Measuring Devices}

A photo of the specimen test setup is provided in Figure 2. The lateral displacement was measured on an electro-hydraulic servo actuator equipped with a displacement sensor. The strains of the steel tube were measured by strain gauges, which were installed in the steel tube as shown in Figure 3. 
TABLE 4 | Measured strengths of RC.

\begin{tabular}{lccc}
\hline $\mathbf{R C} / \boldsymbol{\gamma}(\boldsymbol{\%})$ & $\boldsymbol{f}_{\text {cu }} / \mathbf{M P a}$ & $\boldsymbol{f}_{\mathrm{c}} / \mathbf{M P a}$ & $\boldsymbol{f}_{\mathrm{c}} / \boldsymbol{f}_{\text {cu }}$ \\
\hline 0 & 46.8 & 37.1 & 0.79 \\
30 & 50.8 & 36.9 & 0.73 \\
70 & 53.8 & 38.2 & 0.71 \\
100 & 50.1 & 36.8 & 0.73 \\
\hline
\end{tabular}

TABLE 5 | Measured Poisson's ratios and elasticity modulus of RC.

\begin{tabular}{|c|c|c|c|c|c|}
\hline \multirow[t]{2}{*}{$\mathrm{RC} / \gamma(\%)$} & \multicolumn{4}{|c|}{$v_{\mathrm{c}}$} & \multirow[t]{2}{*}{$E_{\mathrm{c}} / \times 10^{4} \mathrm{MPa}$} \\
\hline & $0.2 f_{c}$ & $0.4 f_{\mathrm{c}}$ & $0.6 f_{\mathrm{c}}$ & $0.8 f_{c}$ & \\
\hline 0 & 0.16 & 0.19 & 0.20 & 0.21 & 3.72 \\
\hline 30 & 0.17 & 0.19 & 0.19 & 0.22 & 3.84 \\
\hline 70 & 0.18 & 0.18 & 0.21 & 0.21 & 3.89 \\
\hline 100 & 0.18 & 0.19 & 0.20 & 0.21 & 3.67 \\
\hline
\end{tabular}

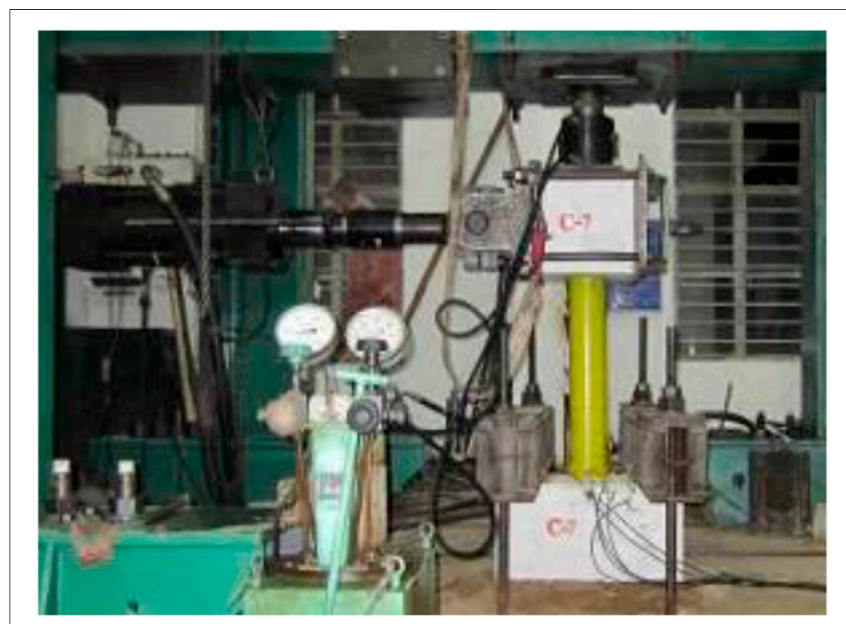

FIGURE 2 | Test setup photo.

\section{Loading System}

Synchronous pressure in a constant vertical load was placed on the top of the column with a $1,500 \mathrm{kN}$ hydraulic jack. In accordance with Specification of testing methods for earthquake resistant building (China Ministry of Construction, 1997), the loading history of $\mathrm{P}$ in this case includes a load control stage and displacement control stage. The load control stage was added to the load level of Py with only one cycle imposed at each load level. During the displacement control stage, three cycles were imposed at incremental displacement levels of $\Delta y, 2 \Delta y$, and $3 \Delta y$, respectively. The cyclic loading speed was controlled at a rate of $5 \mathrm{kN} / \mathrm{s}$ throughout the loading stage. The test was conducted under cyclic loading and stopped when the lateral load decreased to less than $85 \%$ of the Pm at each displacement level. Consistent loading and unloading speeds were controlled to ensure the stability of the test data. The level loading system is depicted in Figure 4.
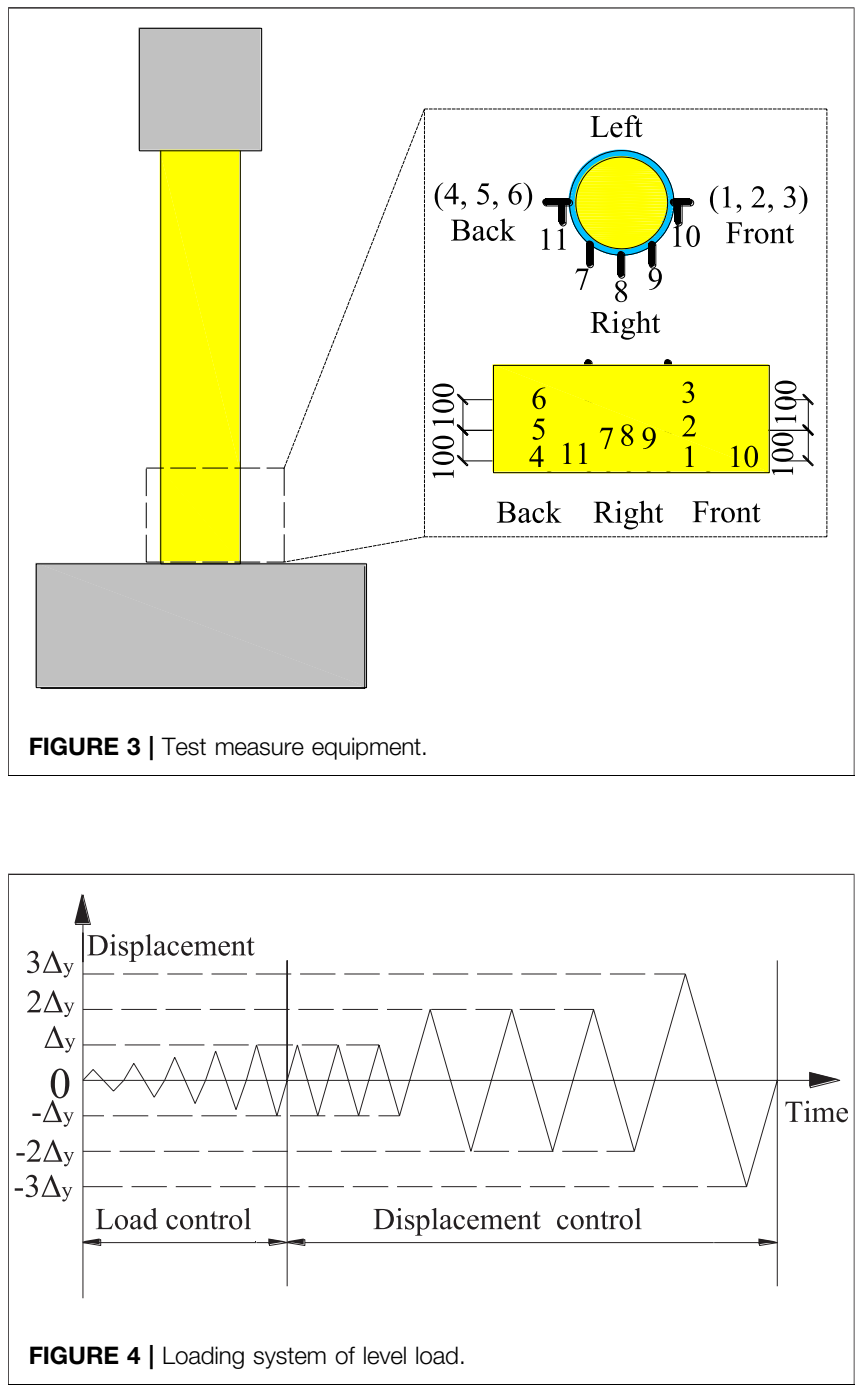

\section{RESULTS AND DISCUSSION}

\section{Failure Modes}

As shown in Figure 5, both the failure process and modes of the specimens were similar to that of ordinary CFST columns in this test. Buckling failure at the bottom of the steel tube was observed as the main failure mode and a relatively obvious buckling wave was observed in the front and back sides of the specimens. Upon buckling failure, the strain of the external steel tube had reached عy. To this effect, the steel tube buckling was elastic-plastic.

After the test, the external steel tubes of the specimens were manually cut to observe the failure mode of the core RC. As shown in Figure 5, no transverse cracks were found along the column height scope. Crushing failure of the RC at the bottom of the column was the main failure mode. The failure area mainly fell within $40 \mathrm{~mm}$ away the bottom of the specimen. Straight seam welding was applied in all of the external steel tubes. No cracks were observed in the welds at any point during the loading process; the welding levels all satisfied the given technical requirements. 


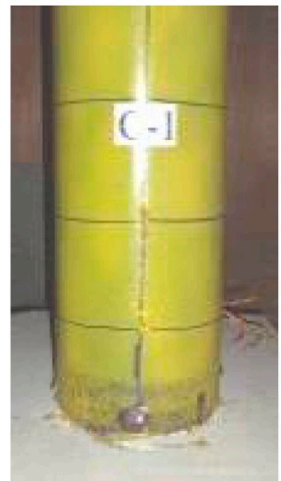

A $\mathrm{C}-1$

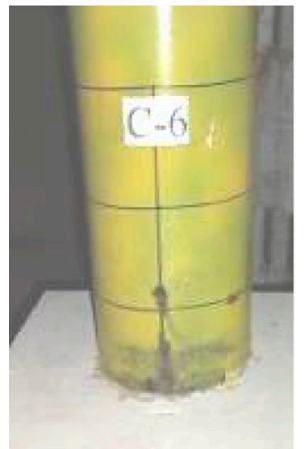

F $\mathrm{C}-6$

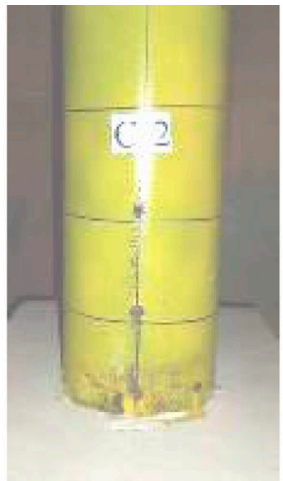

B $\mathrm{C}-2$

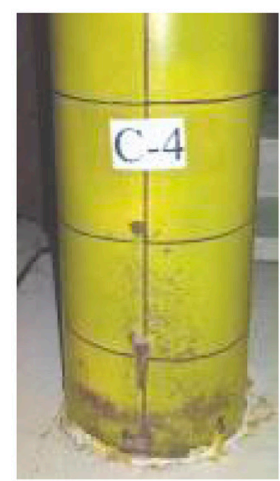

C $\mathrm{C}-3$

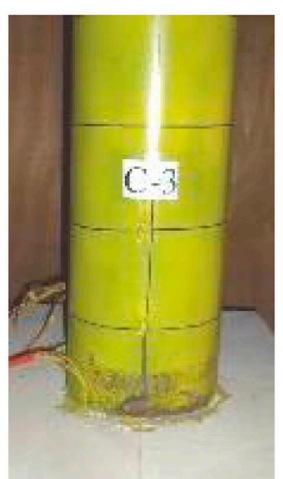

D C-4

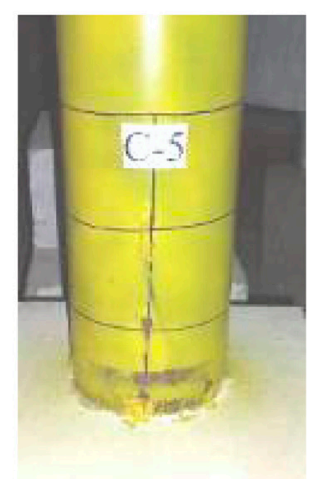

E C-5

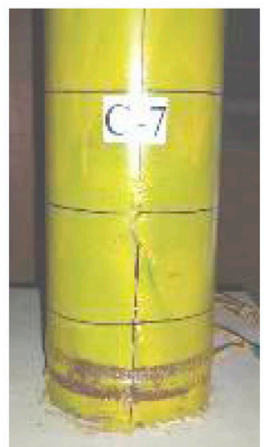

G $\mathrm{C}-7$

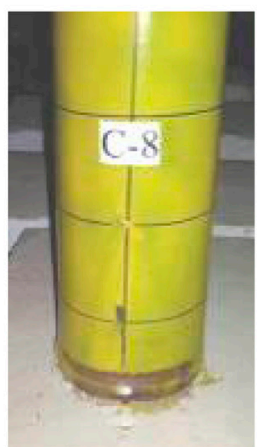

H C-8

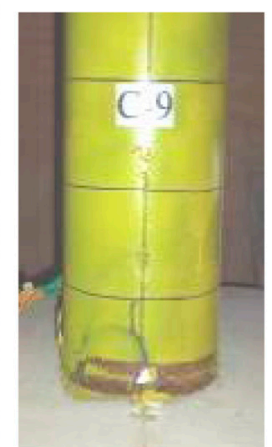

I C-9

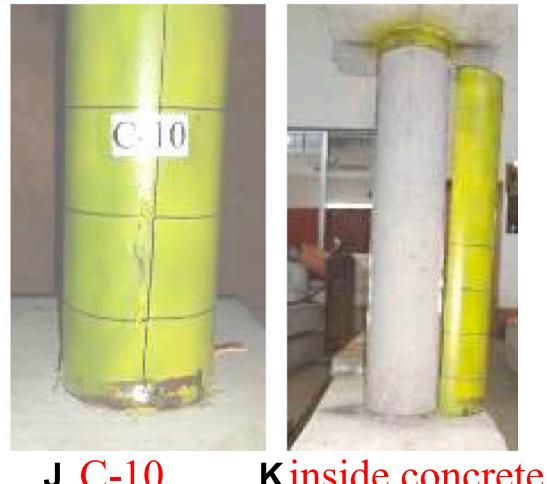

FIGURE 5 | Failure mode of specimens.

The average plastic hinge height in specimens with singleparameter-deviation of $\gamma$ ranged between 27 and $30 \mathrm{~mm}$, the average lengths along the surface of the steel tube ranged from 158 to $190 \mathrm{~mm}$, the average heights of the wrecked spray paint scope center were within the range of 48 and $56 \mathrm{~mm}$, and the maximum inter-story drifts were within the scope of $1 / 12$ and $1 / 14$. In specimens with single-parameter-deviation of $\lambda$, the plastic hinge average heights ranged between 29 and $30 \mathrm{~mm}$, the average lengths along the surface of the steel tube ranged from 141 to $168 \mathrm{~mm}$, the average heights of the wrecked spray paint scope center were within the range of 48 and $56 \mathrm{~mm}$, and the maximum inter-story drifts were within the scope of $1 / 12$ and $1 / 14$. In the specimens with single-parameter-deviation of $n$, the plastic hinge average heights ranged between 16 and $50 \mathrm{~mm}$, the plastic hinges ran through the surfaces of the steel tubes, the average heights of the wrecked spray paint scope center were within the range of 35 and $55 \mathrm{~mm}$, and the maximum inter-story drifts were within the scope of $1 / 13$. In general, the average height of the wrecked spray paint scope center in each specimen was double the plastic hinge average height.

Before failure, the external steel tube and core RC showed good bonding performance. After failure, the bond performance was still strong even as the surface of the external steel tube was hammered manually. No debonding phenomena occurred, suggesting strong confinement effect of the circular steel tube to the core RC. This further indicates that as per the cyclic loading results, the specimens have high seismic resistance overall.

\section{Hysteresis Curve}

The measured $P-\Delta$ hysteresis curves of the RCFST columns are shown in Figure 6. In the load control stage, the hysteresis curves of all the specimens were linear and synthesized into a straight line. There were no observable changes in the initial elastic stiffness. No significant residual deformations were observed at the end of the load control stage, indicating that the specimens were basically in the elastic state. In the displacement control stage, the load slightly increased and the bearing capacity began to decrease after reaching the peak load. The displacement was still positive after the lateral load was unloaded to zero, which indicates the disappearance of residual deformations. The residual deformations grew more obvious as the cyclic displacement increased.

The hysteresis curves drawn over three circulations at the corresponding displacement level gradually tilted and grew closer to the displacement shaft, which reflects step-degradation of the strength and stiffness and step-accumulation of damage to the specimen over the course of the loading process. However, the hysteresis loops grew increasingly plump, illustrating a gradual increase in energy dissipation capacity. The hysteresis curves all show gradual transitions in shape from fusiform to bow. All are relatively plump except for specimens with single-parameterdeviation of $n$, which show good stability as per the absence of any pinching phenomena.

The hysteresis curves of specimens with single-parameterdeviation of $\gamma$ were similar to those of the ordinary CFSTs, 

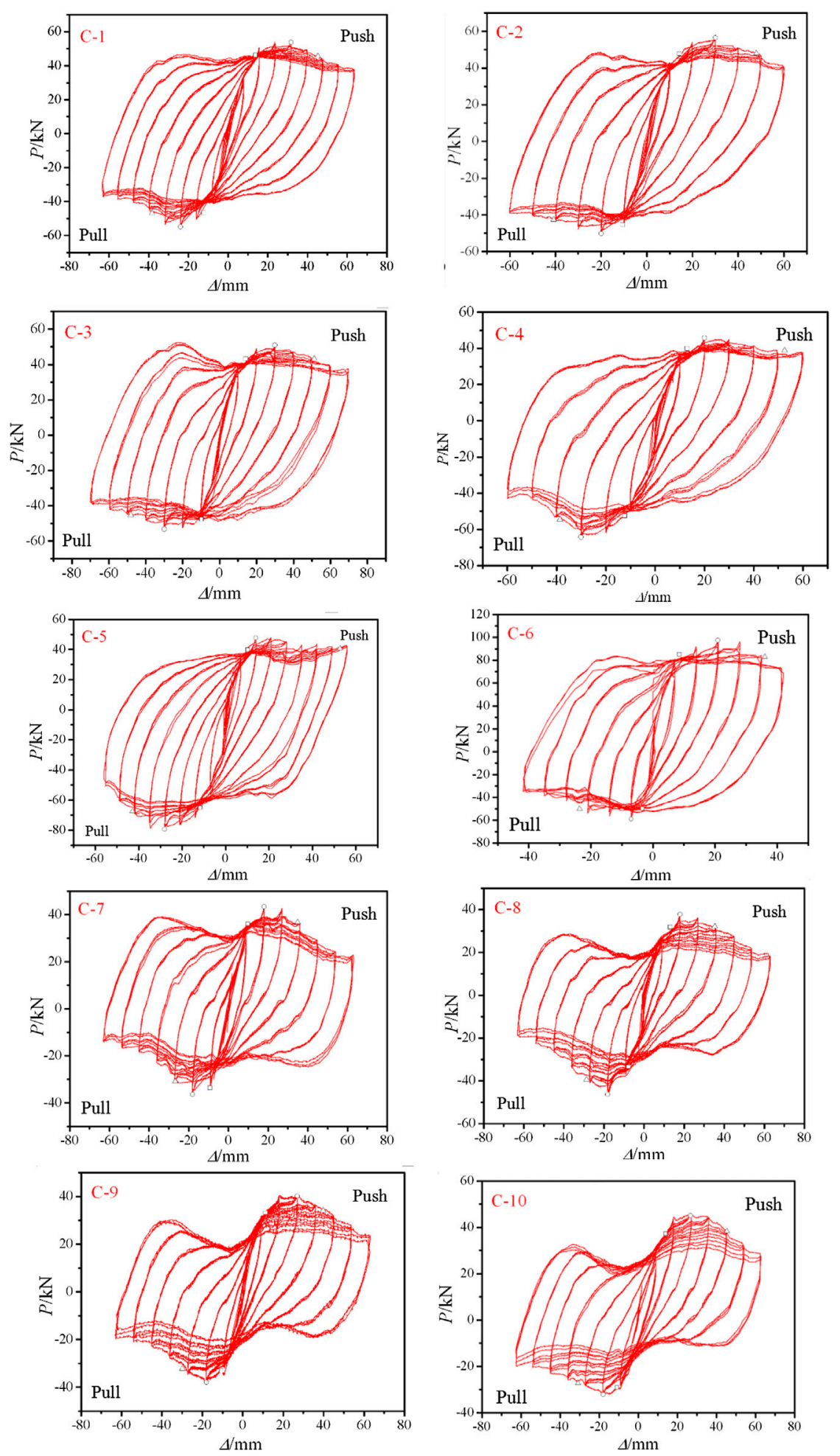

FIGURE 6 | Hysteresis curves of RCFST specimens.

assuming that $\gamma$ exerted little influence on the curves. In the specimens with a single-parameter-deviation of $\lambda$, the yield load, peak load, and failure load gradually increased as $\lambda$ increased. The corresponding points (yield point, peak point, and failure point) hysteresis loops also grew increasingly plump, marking a gradual improvement in energy dissipation capacity. 

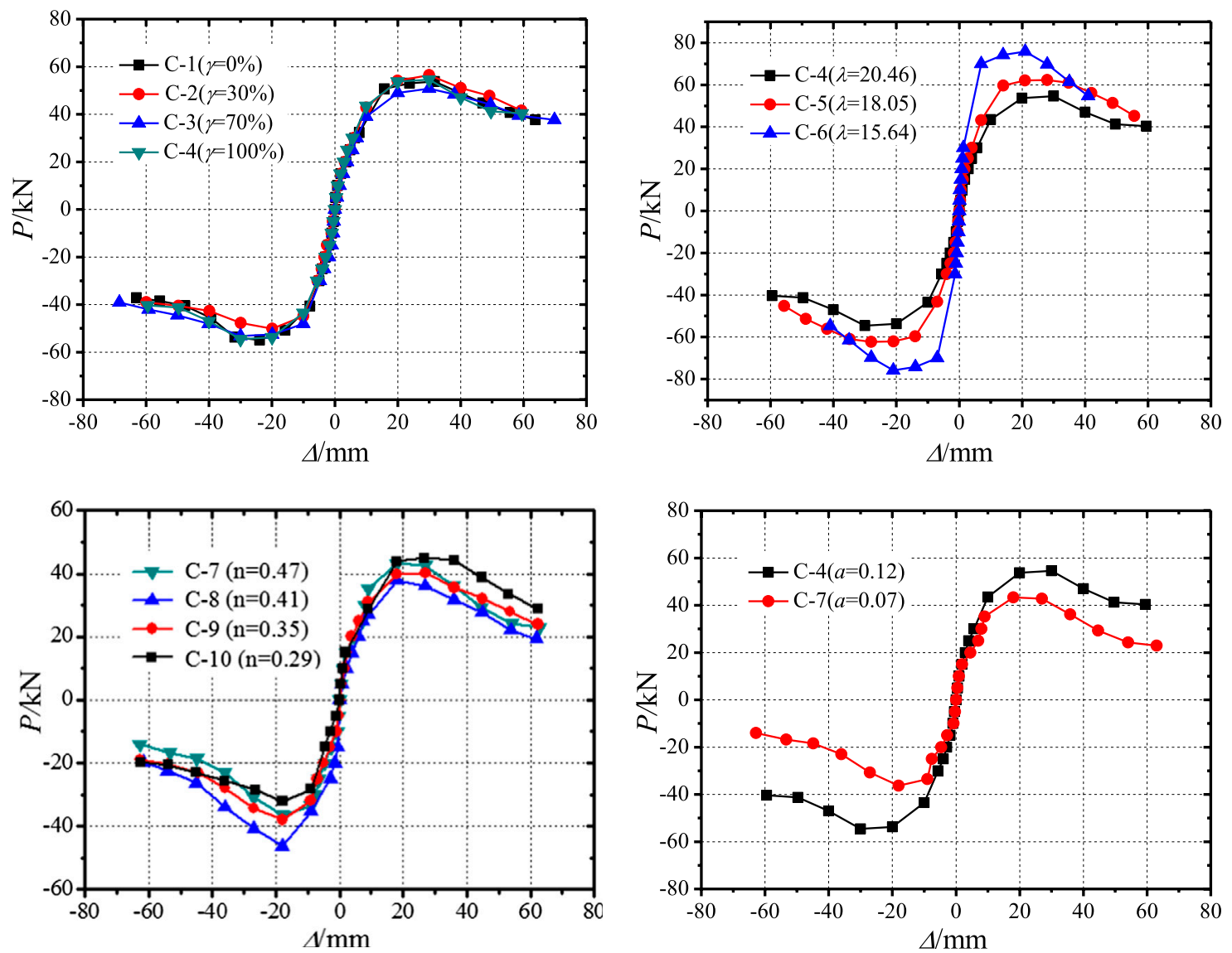

FIGURE 7 | Skeleton curve of RCFST specimens.

Significant pinching phenomena were observed in the later stages of hysteresis curves of specimens with single-parameterdeviation of $n$, and grew more pronounced as $n$ decreased. This can mainly be attributed to weak constraint of the core concrete caused by the smaller steel ratio in the specimens, The restraining effects were weakest in the later stages of loading due to serious local buckling at the bottom of the steel tubes. When the $n$ was smaller, the transverse deformations of the core RC were likely lower than those of the external steel tubes, which degraded the close contact between the steel tube and RC while degrading the corresponding hoop constraint of the steel tube to the core RC. Further, the bearing capacity at each characteristic point of the specimens showed no obvious changes as $n$ increased. Some, in fact, decreased due to the smaller design $n$ values.

The steel ratios of the two specimens C- 4 and C-7 were different. Compared to C-4, C-7 presents a pinch phenomenon at the end of the hysteresis curve because of its smaller wall thickness, indicating that the energy dissipation capacity of C-7 was weaker in the later stages of loading.

\section{Skeleton Curve}

The $P-\Delta$ skeleton curves of the specimens are shown in Figure 7. Some of the specimens had certain deviations in their steel tube perpendicularity due to manufacturing errors, resulting in asymmetrical hysteresis and skeleton curves. The average absolute values of the positive and negative skeleton curves were taken for those biased specimens.

As shown in Figure 7, all the skeleton curves of the specimens were relatively complete with clear ascending, peak, and descending segments. Except for C-6 with bigger $\lambda$, the curves showed relatively smooth descending segments, strong deformation capacity, and high displacement ductility. The shapes of these curves are similar to those of steel structures with no instability. The core RC under the triaxial compression stress state was derived from the restraining effect of the steel tube to the core RC, thus the compression strength and deformation capacity of the core RC improved. Further, the support of the core RC delayed (or prevented) concave buckling in the steel tube and enhanced the stability of the external steel tube. These interactions between the external steel tube and the core RC preserve the distinct material advantages of both parts.

The skeleton curve shapes were similar in specimens with single-parameter-deviation of $\gamma$, with a great deal of overlapping in the elastic stage. It appears that changing the design $\gamma$ had little influence on the initial stiffness. There was some small amplitude separation from the curves upon reaching the peak 


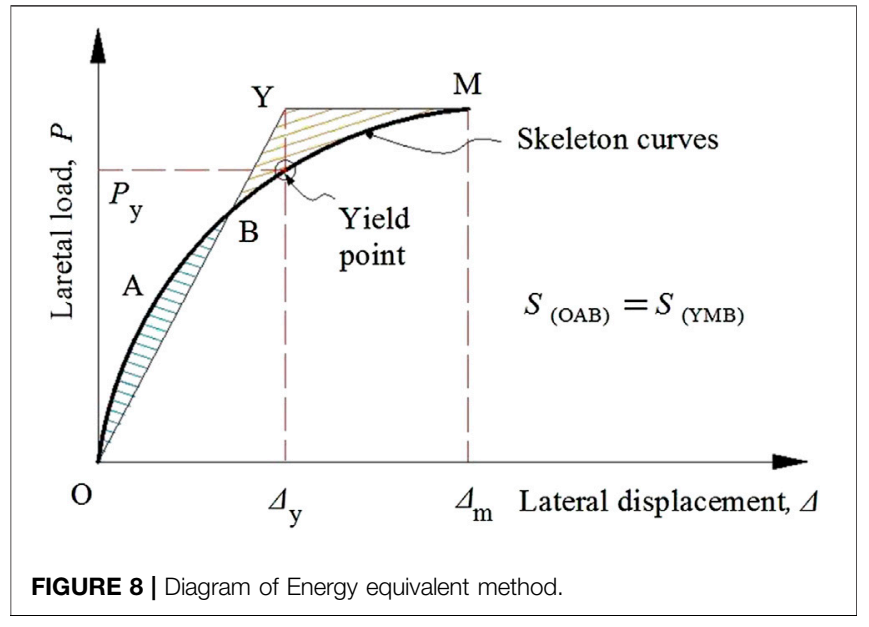

load, but once reaching the descending part, all curves (except C-4 with $100 \% \gamma$ ) synthesized together despite these subtle differences.

On the whole, the RC filled in the steel tube did not degrade the performance of the specimen in terms of negative stiffness. The whole-colored RCA of the core RC presented some initial defects such as micro-cracks in the mechanical crushing and fabrication process. This original damage was responsible for the slight differences in C-4. At the early loading stage, the strong restriction from the steel tube to the core RC limited the development of this type of damage, however, the expanding buckling of the steel tube allowed it to gradually expand - even to the point of affecting the specimen's stiffness in the later descending parts of the curve.

The skeleton curves of the specimens with single-parameterdeviation of $\lambda$ showed obvious discrepancies and grew steeper as $\lambda$ decreased in the elastic stage. The stiffness and the corresponding peak bearing capacity of the specimens increased in the elastic and strengthening stage, but the descending part of the C-6 curve dropped suddenly, revealing weaker deformation capacity in the later loading stage. Changes in the specimens with single-parameterdeviation of $n$ were not attributed to increase in $n$, but also grew pronounced in the descending part of the skeleton curves. C-7 had the largest $n$ and a rather steep skeleton curve descending part, which indicates relatively small failure displacement and deformation capacity.

C-4 and C-7 showed incremental stiffness and exploding peak load capacities at the elastic stage with increase in $\alpha$, but the descending parts of C-4 and C-7 skeleton curves were approximately parallel. This is mainly because the steel tubes buckled as a changed in the late loading stage, which weakened the transverse constraints from the steel tubes with both types of

TABLE 6 | Measured load and displacement at characteristic points.

\begin{tabular}{|c|c|c|c|c|c|c|c|c|c|}
\hline \multirow[t]{2}{*}{ Specimen no. } & \multirow[t]{2}{*}{ Loading direction } & \multicolumn{2}{|c|}{ Yield point } & \multicolumn{2}{|c|}{ Peak point } & \multicolumn{2}{|c|}{ Failure point } & \multirow[t]{2}{*}{$\boldsymbol{\mu}=\Delta_{\mathbf{u}} / \Delta_{\mathbf{y}}$} & \multirow[t]{2}{*}{$\mu_{\mathrm{a}}$} \\
\hline & & $P_{\mathrm{y}}$ & $\Delta_{\mathrm{y}}$ & $P_{m}$ & $\Delta_{\mathrm{m}}$ & $P_{\mathrm{u}}$ & $\Delta_{\mathrm{u}}$ & & \\
\hline \multirow[t]{2}{*}{ C-1 } & Positive & 46.19 & 13.81 & 53.71 & 31.75 & 45.65 & 45.26 & 3.28 & 3.18 \\
\hline & Average & 46.38 & 13.12 & 54.32 & 27.81 & 46.17 & 41.79 & - & \\
\hline \multirow[t]{2}{*}{ C-2 } & Positive & 47.80 & 14.27 & 56.43 & 29.97 & 47.97 & 47.96 & 3.36 & 3.58 \\
\hline & Negative & 45.40 & 10.73 & 50.16 & 19.92 & 42.64 & 40.78 & 3.80 & \\
\hline & Negative & 47.66 & 9.89 & 53.25 & 29.96 & 45.26 & 48.10 & 4.86 & \\
\hline & Average & 45.48 & 12.04 & 52.03 & 29.97 & 44.22 & 49.70 & - & \\
\hline \multirow[t]{3}{*}{ C-4 } & Positive & 39.96 & 13.04 & 45.66 & 20.01 & 38.81 & 52.54 & 3.98 & 3.58 \\
\hline & Negative & 52.53 & 12.35 & 64.24 & 30.01 & 54.60 & 38.61 & 3.12 & \\
\hline & Average & 46.25 & 12.70 & 54.95 & 25.01 & 46.71 & 45.58 & - & \\
\hline \multirow[t]{2}{*}{ C-5 } & Positive & 39.97 & 10.19 & 47.75 & 13.98 & 40.59 & 52.70 & 5.18 & 4.43 \\
\hline & Negative & 64.94 & 11.63 & 79.29 & 27.97 & 67.40 & 42.83 & 3.70 & \\
\hline \multirow[t]{3}{*}{ C-7 } & Positive & 35.91 & 9.68 & 43.31 & 18.02 & 36.81 & 34.91 & 3.54 & 3.32 \\
\hline & Negative & 32.57 & 8.85 & 36.35 & 18.01 & 30.90 & 26.77 & 2.86 & \\
\hline & Average & 34.24 & 9.27 & 39.83 & 18.02 & 33.86 & 30.84 & - & \\
\hline \multirow[t]{3}{*}{ C-8 } & Positive & 31.80 & 13.12 & 37.72 & 17.99 & 32.06 & 35.37 & 2.70 & 3.19 \\
\hline & Negative & 33.32 & 7.81 & 46.33 & 18.04 & 39.38 & 28.7 & 3.67 & \\
\hline & Average & 32.56 & 10.47 & 42.03 & 18.02 & 35.72 & 32.04 & - & \\
\hline \multirow[t]{3}{*}{ C-9 } & Positive & 33.17 & 11.31 & 40.21 & 27.02 & 34.18 & 39.74 & 3.51 & 3.17 \\
\hline & Negative & 33.10 & 10.57 & 37.95 & 17.93 & 32.26 & 29.95 & 2.83 & \\
\hline & Average & 33.14 & 10.94 & 39.08 & 22.48 & 33.22 & 34.85 & - & \\
\hline \multirow[t]{3}{*}{ C-10 } & Positive & 37.12 & 14.01 & 45.01 & 26.72 & 38.26 & 45.33 & 3.24 & 3.04 \\
\hline & Negative & 29.06 & 10.8 & 32.07 & 17.91 & 27.26 & 30.82 & 2.85 & \\
\hline & Average & 33.09 & 12.41 & 38.54 & 22.32 & 32.76 & 38.08 & - & \\
\hline
\end{tabular}




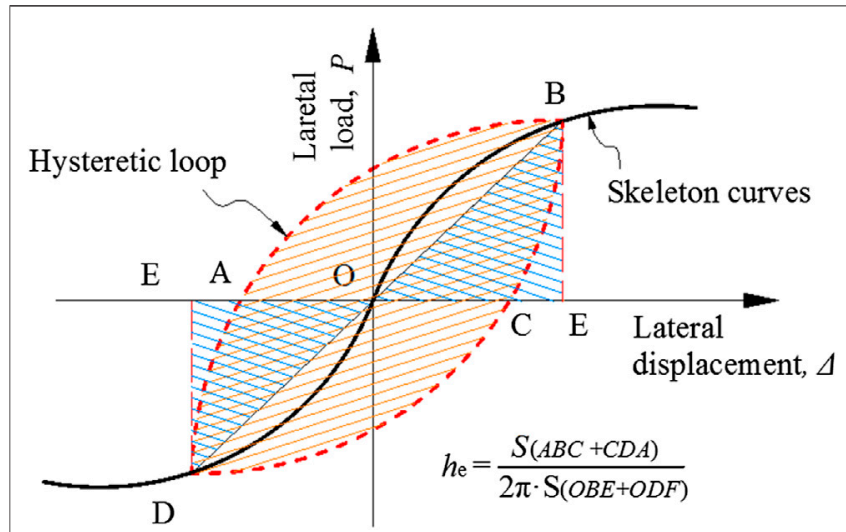

FIGURE 9 | Calculation diagram of $h_{\mathrm{e}}$.

wall thickness to the core RC. The advantages originating in larger wall thickness were not retained. The chosen $n$ was only related to the $\mathrm{RC}$ in these cases. The equal vertical loads were pressurized on C-4 and C-7, so the steel tubes lost most of their vertical load bearing capacity due to buckling at the later loading stages. The core RC bore most of the vertical loads. At that moment, the axial loads borne by the core $\mathrm{RC}$ of C-4 and C-7 were approximately equal, thus there were few changes observed in the descending part related to the stiffness of C-4 and C-7.

\section{Ductility}

Ductility reflects the plastic deformation capacity of engineered structural components under seismic testing; to this effect, it was an important performance index in the present study. The initial yield points obtained through the energy equivalent method are shown in Figure 8. A bi-linear curve $O Y-Y M$ was drawn to replace the original $P-\triangle$ curve. The total area of the curve $O A B M$ equals the broken line $O Y-Y M$, namely, $\mathrm{S}_{O A B}=\mathrm{S}_{B Y M}$. The calculated $\mu$ and characteristic points are listed in Table 6.

As shown in Table 6, the actual values of $\mu$ were larger than 3 in this case indicating good ductility performance. In specimens with single-parameter-deviation of $\gamma$, the yield load, peak load, failure load, and the corresponding displacement were similar, indicating that $\gamma$ had no significant influence on the specimen's ductility.

\section{Energy Dissipation Capacity}

The equivalent viscous damping coefficient $\left(h_{\mathrm{e}}\right)$ is another important criterion for judging energy dissipation capacity in the seismic performance research of engineered structures. When $S$ denotes the area, $S_{A B C}$ and $S_{C D A}$ are areas under $A B C$ and CDA, respectively; $\mathrm{S}_{O B E}$ and $S_{O D F}$ are areas within triangles $\mathrm{OBE}$ and ODF, respectively, as shown in Figure 9. The $h_{\mathrm{e}}$ value was taken here from the first cycle under cyclic displacement at various levels, as listed in Table 7.

As shown in Table 6, the $h_{\mathrm{e}}$ of the specimens ranged from 0.152 to 0.190 at yield, from 0.210 to 0.299 at peak, and fell between 0.305 and 0.460 at failure, respectively. These values in ordinary RC columns generally range from 0.1 to 0.2 at failure, which are equivalent to the $h_{\mathrm{e}}$ at yield, $1 / 2$ at peak, and $1 / 3$ at failure in the RCFST specimens tested in this study, respectively.

\section{Stiffness Degradation}

The secant stiffness $\left(K_{\mathrm{i}}\right)$ is the stiffness degradation representative of specimens placed under repeated loading cycles. $K_{\mathrm{i}}$ is expressed as follows:

$$
K_{\mathrm{i}}=\left(\left|+F_{\mathrm{i}}\right|+\left|-F_{\mathrm{i}}\right|\right) /\left(\left|+X_{\mathrm{i}}\right|+\left|-X_{\mathrm{i}}\right|\right)
$$

where $\left(+F_{\mathrm{i}}\right)$ and $\left(+X_{\mathrm{i}}\right)$ are the positive maximum load and corresponding deformation of the $i$ th loop, respectively; $\left(-F_{\mathrm{i}}\right)$ and $\left(-X_{\mathrm{i}}\right)$ are the negative maximum load and corresponding deformation of the $i$ th loop.

The uniformity of stiffness vs. displacement results under the given design parameters were analyzed as shown in Figure 10 to observe the stiffness degradation rules of those with singleparameter-deviation. The measured stiffness for different characteristic points are listed in Table 8. In the specimens with single-parameter-deviation of $\gamma$, the stiffness degradation curves basically overlapped; the stiffness degradation rate of C-1 was slightly smaller, mainly because a part of the cement mortar adhered on the surface of the RCA and decreased the elastic modulus of the RC, accelerating the cracking/crushing trends of the $\mathrm{RC}$ under low reversed cyclic loading. In general, the stiffness degradation rate of C-1 was relatively low.

The stiffness degradation rule of the RCFST was basically identical under different $\gamma$ values. In the specimens with singleparameter-deviation of $\lambda$, the stiffness degraded more slowly as $\lambda$ increased near the yield point. However, the stiffness degradation rates grew more uniform as the cyclic displacement increased. In the specimens with singleparameter-deviation of $n$, the secant stiffness $\left(K_{\mathrm{i}}\right)$ increased with $n$. This can be mainly attributed to the increasingly obvious second-order effects in the later stages of the test. The stiffness degradation curves of C-4 and C-7 were very similar and their $K_{\mathrm{i}}$ of were basically identical. Again, it appears that the wall thickness advantage disappeared in the descending part of the stiffness curve within the scope of the $\alpha$ imposed in this test.

\begin{tabular}{lccccccccc}
\hline \multicolumn{2}{l}{ TABLE 7 | Measured $h_{\mathrm{e}}$ at characteristic points. } \\
\hline Specimen no. & $\mathbf{C - 1}$ & $\mathbf{C - 2}$ & $\mathbf{C - 3}$ & $\mathbf{C - 4}$ & $\mathbf{C - 5}$ & $\mathbf{C - 6}$ & $\mathbf{C - 7}$ & $\mathbf{C - 8}$ & $\mathbf{C}$ \\
\hline$\Delta_{\mathrm{y}}$ & 0.152 & 0.190 & 0.175 & 0.179 & 0.161 & 0.157 & 0.187 & 0.163 & 0.163 \\
$\Delta_{\mathrm{m}}$ & 0.248 & 0.257 & 0.299 & 0.234 & 0.213 & 0.212 & 0.234 & 0.239 & 0.233 \\
$\Delta_{\mathrm{u}}$ & 0.402 & 0.406 & 0.460 & 0.433 & 0.433 & 0.378 & 0.356 & 0.338 & 0.335 \\
\end{tabular}



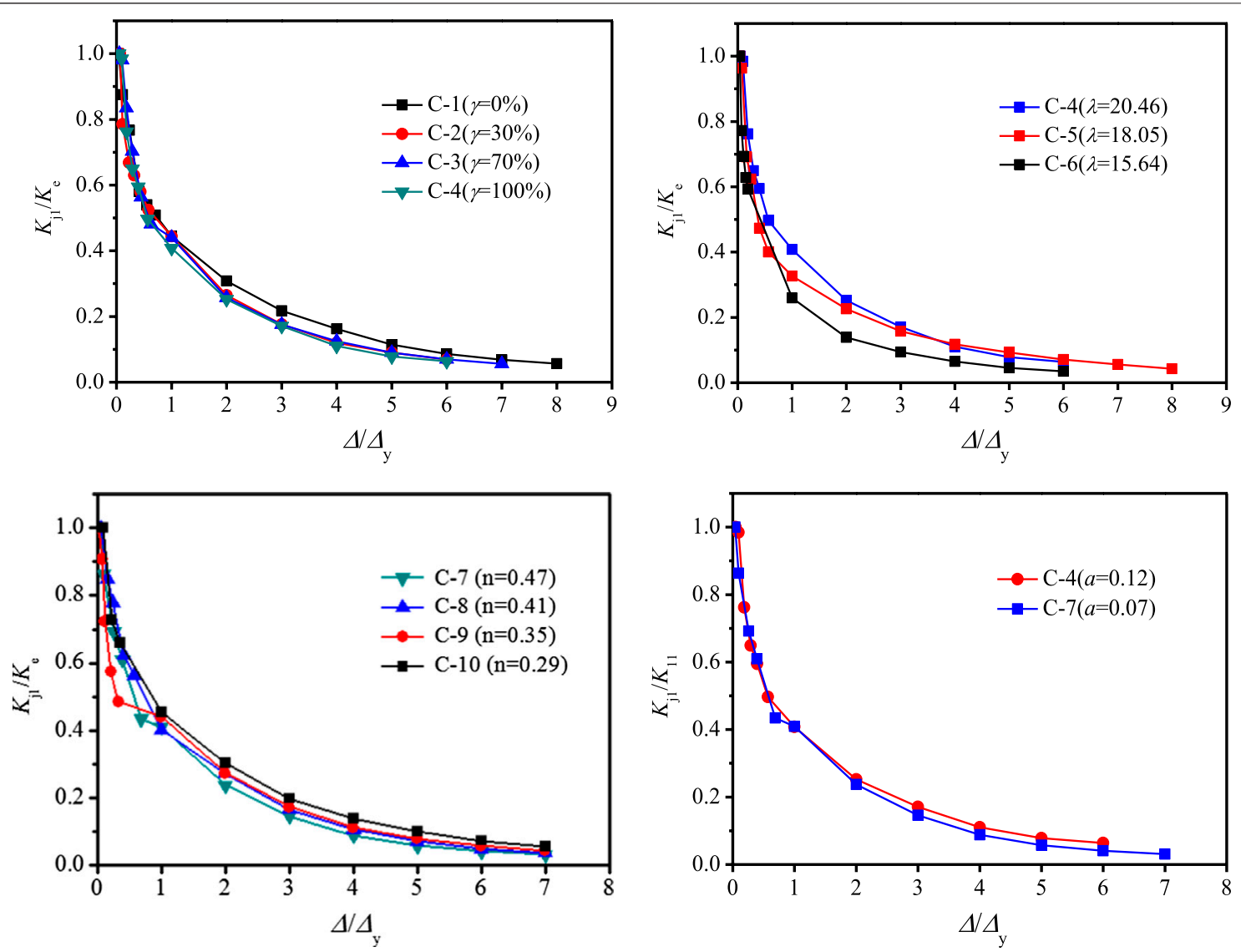

FIGURE 10 | Uniformization analysis of stiffness vs. displacement.

TABLE 8 | Measured stiffness at characteristic points.

\begin{tabular}{|c|c|c|c|c|c|c|c|}
\hline No. & $K_{\mathrm{e}}(\mathrm{kN} / \mathrm{mm})$ & $K_{\mathrm{y}}(\mathrm{kN} / \mathrm{mm})$ & $K_{\mathrm{m}}(\mathrm{kN} / \mathrm{mm})$ & $K_{\mathrm{u}}(\mathrm{kN} / \mathrm{mm})$ & $K_{\mathrm{y}} / K_{\mathrm{e}}$ & $K_{\mathrm{m}} / K_{\mathrm{e}}$ & $\kappa_{\mathrm{u}} / K_{\mathrm{e}}$ \\
\hline C-1 & 10.43 & 3.54 & 1.95 & 1.10 & 0.34 & 0.19 & 0.11 \\
\hline C-2 & 9.87 & 3.73 & 2.14 & 1.02 & 0.38 & 0.22 & 0.10 \\
\hline C-3 & 9.90 & 3.78 & 1.74 & 0.89 & 0.38 & 0.18 & 0.09 \\
\hline$C-5$ & 18.87 & 4.81 & 3.03 & 1.13 & 0.25 & 0.16 & 0.06 \\
\hline C-6 & 38.46 & 9.62 & 5.60 & 2.23 & 0.25 & 0.15 & 0.06 \\
\hline C-7 & 9.32 & 3.70 & 2.21 & 1.10 & 0.40 & 0.24 & 0.12 \\
\hline C-10 & 6.99 & 2.67 & 1.73 & 0.86 & 0.38 & 0.25 & 0.12 \\
\hline
\end{tabular}

\section{BENDING BEARING CAPACITY CALCULATION}

The existing research on CFST structures is relatively sophisticated. A series of relevant specifications currently stand [e.g., Chinese standards CECS254:2012 (China Association for Engineering Construction Standardization, 1992), DL/T5085-1999 (China Electric Power Industry Standard, 1999), and DBJ13-51-2003 (Construction Department of Fujian Province, 2003), the US standard AISC-LRFD (1999) (American Institute of Steel
Construction, 1999), the UK standard BS5400 (2005) (Bulky Standards Institutions, 2005), and the European EC4 (1994) (European Committee for Standardization, 2004)]. Zhu (1989) founded that the skeleton curve under low cyclic repeated loading is closer to the load displacement curve under static monotonous loading. To determine whether existing strength calculation methods for CFST components under static monotonous loading apply to the RCFCST components under low cyclic repeated loading, the test data given above were input to the above codes to calculate the compression-flexure strength of the 
TABLE 9 | Contrast results between $N_{\mathrm{u}}^{\mathrm{t}}$ and $N_{\mathrm{u}}^{\mathrm{c}}$.

\begin{tabular}{|c|c|c|c|c|c|c|c|c|c|c|c|c|c|}
\hline \multirow[t]{2}{*}{ No. } & \multirow[t]{2}{*}{$\mathbf{N}_{\mathrm{u}}^{\mathrm{t}} / \mathbf{k N}$} & \multicolumn{2}{|c|}{ CECS254:2012 } & \multicolumn{2}{|c|}{ DL/T5085-1999 } & \multicolumn{2}{|c|}{ DBJ13-51-2003 } & \multicolumn{2}{|c|}{$\begin{array}{c}\text { AISC-LRFD } \\
\text { (1999) }\end{array}$} & \multicolumn{2}{|c|}{ BS5400 } & \multicolumn{2}{|c|}{$\begin{array}{c}\text { EC4 } \\
(1994)\end{array}$} \\
\hline & & $\mathbf{N}_{\mathrm{u}}^{\mathrm{c}} / \mathbf{k N}$ & $\mathbf{N}_{\mathrm{u}}^{\mathrm{t}} / \mathbf{N}_{\mathrm{u}}^{\mathrm{c}}$ & $\mathbf{N}_{\mathrm{u}}^{\mathrm{c}} / \mathbf{k N}$ & $\mathbf{N}_{\mathrm{u}}^{\mathrm{t}} / \mathbf{N}_{\mathrm{u}}^{\mathrm{c}}$ & $\mathbf{N}_{\mathrm{u}}^{\mathrm{c}} / \mathbf{k N}$ & $\mathbf{N}_{\mathrm{u}}^{\mathrm{t}} / \mathbf{N}_{\mathrm{u}}^{\mathrm{c}}$ & $\mathbf{N}_{\mathrm{u}}^{\mathrm{c}} / \mathbf{k} \mathbf{N}$ & $\mathbf{N}_{\mathrm{u}}^{\mathrm{t}} / \mathbf{N}_{\mathrm{u}}^{\mathrm{c}}$ & $\mathbf{N}_{\mathrm{u}}^{\mathrm{c}} / \mathbf{k N}$ & $\mathbf{N}_{\mathrm{u}}^{\mathrm{t}} / \mathbf{N}_{\mathrm{u}}^{\mathrm{c}}$ & $\mathbf{N}_{\mathrm{u}}^{\mathrm{c}} / \mathbf{k N}$ & $\mathbf{N}_{\mathrm{u}}^{\mathrm{t}} / \mathbf{N}_{\mathrm{u}}^{\mathrm{c}}$ \\
\hline $\mathrm{C}-1$ & 54.32 & 44.21 & 0.76 & 60.47 & 0.90 & 69.00 & 0.79 & 37.90 & 1.45 & 28.71 & 1.74 & 47.88 & 0.92 \\
\hline C-2 & 53.30 & 42.13 & 0.77 & 58.79 & 0.91 & 68.25 & 0.78 & 36.82 & 1.47 & 30.01 & 1.63 & 48.15 & 0.90 \\
\hline C-3 & 52.03 & 41.66 & 0.76 & 58.82 & 0.88 & 68.29 & 0.76 & 36.01 & 1.47 & 31.03 & 1.54 & 48.35 & 0.88 \\
\hline C-4 & 54.95 & 42.38 & 0.80 & 58.95 & 0.93 & 68.32 & 0.80 & 37.00 & 1.51 & 29.88 & 1.69 & 48.10 & 0.93 \\
\hline$C-5$ & 63.52 & 48.57 & 0.81 & 66.84 & 0.95 & 78.23 & 0.81 & 42.00 & 1.53 & 30.94 & 1.91 & 54.64 & 0.95 \\
\hline C-6 & 78.96 & 40.92 & 1.04 & 64.83 & 1.22 & 82.51 & 0.96 & 34.00 & 2.37 & 49.09 & 1.50 & 59.47 & 1.26 \\
\hline $\mathrm{C}-7$ & 39.83 & 23.65 & 0.93 & 37.18 & 1.07 & 39.85 & 1.00 & 14.25 & 2.88 & 23.59 & 1.58 & 27.51 & 1.24 \\
\hline C-8 & 42.03 & 26.74 & 0.91 & 39.61 & 1.06 & 41.14 & 1.02 & 16.33 & 2.63 & 20.64 & 1.91 & 42.95 & 0.99 \\
\hline C-9 & 39.08 & 29.83 & 0.79 & 42.03 & 0.93 & 41.87 & 0.93 & 18.41 & 2.16 & 17.69 & 2.07 & 43.04 & 0.91 \\
\hline C-10 & 38.54 & 32.93 & 0.74 & 44.45 & 0.87 & 42.04 & 0.92 & 20.49 & 1.90 & 14.75 & 2.45 & 43.12 & 0.90 \\
\hline
\end{tabular}

TABLE $10 \mid N_{\mathrm{u}}^{\mathrm{t}} / N_{\mathrm{u}}^{\mathrm{c}}$ demographic characteristics of specimens.

\begin{tabular}{|c|c|c|c|c|c|c|}
\hline $\begin{array}{l}\text { Demographic } \\
\text { characteristic }\end{array}$ & CECS254:2012 & DL/T5085-1999 & DBJ13-51-2003 & AISC-LRFD (1999) & BS5400 & EC4 (1994) \\
\hline Average value & 0.83 & 0.97 & 0.88 & 1.94 & 1.80 & 0.99 \\
\hline Variance & 0.0095 & 0.0123 & 0.0097 & 0.2913 & 0.0854 & 0.0202 \\
\hline Coefficient of variability & 0.1171 & 0.1140 & 0.1121 & 0.2785 & 0.1623 & 0.1439 \\
\hline
\end{tabular}

specimens. The measured results $N_{\mathrm{u}}^{\mathrm{t}}$ and the calculated results $N_{\mathrm{u}}^{\mathrm{c}}$ were then compared. The results and demographic characteristics of the specimens are given in Tables $\mathbf{9 , 1 0}$.

The calculation results obtained by AISC-LRFD (1999) (American Institute of Steel Construction, 1999), BS5400 (2005) (Bulky Standards Institutions, 2005) were much smaller than the test results, indicating that these designs are relatively conservative. This is mainly due to the superposition calculation theory applied in the two specifications. The triaxial compression strength of the core concrete was calculated under BS5400 (2005) to determine the superpositioned bearing capacity of the external steel tube and core concrete, but a smaller amplitude discount in the core concrete bearing capacity drove the calculation results below the measurement results after the superposition. AISCLRFD (1999) does not reveal improved bearing capacity, namely, the confined effect of the external steel tube is not considered, so the calculated values were significantly lower than the measured values. AISC-LRFD (1999) is more conservative than BS5400 (2005). Compared to AISC-LRFD (1999), BS5400 (2005), the values calculated under EC4 (1994) (European Committee for Standardization, 2004) coincided better with the measured values. This was mainly because the confined effect of the steel tube under by EC4 (1994) improved the results. However, EC4 (1994) was not proposed in the design calculation of the compression-bending capacity of RCFST columns under cyclic loading.

The CECS254:2012, DL/T5085-1999, and DBJ13-51-2003 standards use a unified theory for computing RCFST compression-bending capacity. The CFST components can thus be unified under various stress states for calculating the bearing capacity. This design is based on a large number of experimental results processed by data regression and summarization. The discreteness between the calculated ultimate bearing capacity of the RCFST components through DL/T5085-1999 and the test data was relatively small here. DL/T5085-1999 proved most accurate in the design calculation of RCFST column compression-bending capacity under repeated loading cycles. The test results were lower than the CECS254: 2012 or DBJ13-51-2003 calculations, which would result in significant safety hazards if put into practice. Neither standard is suitable for the strength design of RCFST components under cyclic loading conditions.

\section{CONCLUSION}

A seismic performance test and bending bearing capacity calculation were performed in this study to analyze 10 circular RCFST columns with various design parameters. The conclusions can be summarized as follows.

- The failure processes and modes of the specimens are similar to those of ordinary CFST columns. Buckling failure at the bottom of the steel tube is the main failure mode and a relatively obvious buckling wave is present at the front and back sides of the specimens.

- All specimens have plump hysteresis curves which transition in shape from spindle to bow, except the specimens with single-parameter-deviation of $n$. There is no obvious pinching phenomena in the specimen hysteresis curves, indicating good stability.

- The hysteresis curves of specimens with single-parameterdeviation of $\gamma$ are basically similar to those of the ordinary CFSTs, which suggests that the $\gamma$ in the existing parameter range has little influence on the curves. RC can be applied in engineered bearing structures under the given seismic performance requirements. 
- The actual $\mu$ values of the specimens are all larger than 3, showing good ductility performance.

- The $h_{\mathrm{e}}$ values of the specimens fall within the range of 0.152 and 0.190 at yield, range from 0.210 to 0.299 at peak, and range between 0.305 and 0.460 at failure, respectively, while those of ordinary reinforced concrete columns generally range from 0.1 to 0.2 at failure - this is equivalent to the $h_{\mathrm{e}}$ at yield, $1 / 2$ at peak, and $1 / 3$ at failure of the RCFST specimens, respectively.

- DL/T5085-1999 is a suitable standard for the design calculation of compression-bending capacity in RCFST columns under cyclic loading conditions.

\section{DATA AVAILABILITY STATEMENT}

The original contributions presented in the study are included in the article/Supplementary Material, further inquiries can be directed to the corresponding author/s.

\section{REFERENCES}

American Institute of Steel Construction (1999). AISC-LRFD (1999). Load and resistance factor design specification for structural steel buildings. Chicago, IL: American Institute of Steel Construction.

Amnon, K. (2003). Properties of concrete made with recycled aggregate from partially hydrated old concrete. Cement Concr. Res. 33 (5), 703-711. doi:10. 1016/S0008-8846(02)01033-5

Bulky Standards Institutions (2005). BS5400 (2005). Steel, concrete and composite bridges, Part 5: Code of practice for design of composite bridges. London, UK: Bulky Standards Institutions.

China Association for Engineering Construction Standardization (1992). CECS254:2012. Technical specification of hollow and solid concrete-filled steel tubular structures. Beijing, China: China Planning Press [in Chinese, with English summary].

China Electric Power Industry Standard (1999). DL/T5085-1999. Code for design of steel-concrete composite structure. Beijing, China: China Electric Power Press [in Chinese, with English summary].

China Ministry of Construction (1997). JGJ101-1996. Specification of testing methods for earthquake resistant building. Beijing, China: China Building Industry Press [in Chinese, with English summary].

Chinese GB Standards (2002). GB/T228-2002. Metallic materials: tensile testing at ambient temperature. Beijing, China: China Standards Press [in Chinese, with English summary].

Construction Department of Fujian Province (2003). DBJ13-51-2003. Technical specification for concrete- filled steel tubular. Fuzhou, China: Construction Department of Fujian Province [in Chinese, with English summary].

de Brito, J., Ferreira, J., Pacheco, J., Soares, D., and Guerreiro, M. (2016). Structural, material, mechanical and durability properties and behaviour of recycled aggregates concrete. J. Build. Eng. 37 (6), 1-16. doi:10.1016/j.jobe. 2016.02.003

Dong, J.-F., Wang, Q.-Y., and Guan, Z.-W. (2016). Material and structural response of steel tube confined recycled earthquake waste concrete subjected to axial compression. Mag. Concr. Res. 68 (6), 271-282. doi:10.1680/jmacr.14. 00357

Etxeberria, M., Vázquez, E., Marí, A., and Barra, M. (2007). Influence of amount of recycled coarse aggregates and production process on properties of recycled aggregate concrete. Cement Concr. Res. 37 (5), 735-742. doi:10.1016/j. cemconres.2007.02.002

European Committee for Standardization (2004). EN1994-1-1:2004. Design of composite steel and concrete structure. Part 1-1: general rules and rules for buildings. Brussels, Belgium: European Committee for Standardization.

\section{AUTHOR CONTRIBUTIONS}

DX: Conceptualization, Methodology, Writing- Original draft preparation; ZC: Investigation; CZ: Visualization, WritingReviewing and Editing.

\section{FUNDING}

This work was supported by the Systematic Project of Guangxi Key Laboratory of Disaster Prevention and Structural Safety (2019ZDK017), Key Project of Scientific Research and Development Fund of Kangda College of Nanjing Medical University (KD2018KYJJZD009), Training Fund for Young Talents of Lianyungang Maternal and Child Health Hospital (KY201910) and Zhejiang Provincial Natural Science Foundation of China (LQ20E080003).

Geng, Y., Wang, Y., and Chen, J. (2015). Time-dependent behavior of recycled aggregate concrete-filled steel tubular columns. J. Struct. Eng. 141 (10), 04015011. doi:10.1061/(asce)st.1943-541x.0001241

Hansen, T. C., and Boegh, E. (1985). Elasticity and drying shrinkage of recycled aggregate concrete. ACI J. 82 (5), 648-652.

Huang, Y., Sun, Y., Sun, H., and Wang, Q. (2015). Theoretical analysis on mechanical behavior of axially loaded recycled aggregate concrete filled steel tubes. Math. Probl Eng. 2015, 1-14. doi:10.1155/2015/270469

Liu, Y., Zha, X., and Gong, G. (2012). Study on recycled-concrete-filled steel tube and recycled concrete based on damage mechanics. J. Constr. Steel Res. 71 143-148. doi:10.1016/j.jcsr.2011.10.023

Mohanraj, E. K., Kandasamy, S., and Malathy, R. (2011). Behaviour of steel tubular stub and slender columns filled with concrete using recycled aggregates. J. $S$. Afr. Inst. Civ. Eng. 53 (2), 31-38. doi:10.4314/jcerp.v6i1.45184

National Standards of the People's Republic of China (2003). GB50081-2002. Standard for test method of mechanical properties on ordinary concrete. Beijing, China: China Building Industry Press [in Chinese, with English summary].

Niu, H.-c., and Cao, W.-l. (2015). Full-scale testing of high-strength RACFST columns subjected to axial compression, Mag. Concr. Res. 67 (5), 257-270. doi:10.1680/macr.14.00198

Shi, X.-S., Wang, Q.-Y., Zhao, X.-L., and Collins, F. G. (2015). Structural behaviour of geopolymeric recycled concrete filled steel tubular columns under axial loading. Construct. Build. Mater. 81, 187-197. doi:10.1016/.conbuildmat.2015.02.035

Tam, V. W. Y., Wang, Z.-B., and Tao, Z. (2014). Behaviour of recycled aggregate concrete filled stainless steel stub columns. Mater. Struct. 47 (1), 293-310. doi:10.1617/s11527-013-0061-1

Wang, Y., Chen, J., and Geng, Y. (2015). Testing and analysis of axially loaded normal-strength recycled aggregate concrete filled steel tubular stub columns. Eng. Struct. 86, 192-212. doi:10.1016/j.engstruct.2015.01.007

Wu, B., Zhao, X. Y., Liu, W., Liu, Q. X., and Xu, Z. (2011). Axial strengths of concrete stub columns filled with demolished concrete segments/lumps. Adv. Sci. Lett. 4 (8-10), 2719-2726. doi:10.1166/asl.2011.1727

Wu, B., Zhao, X.-Y., Zhang, J.-S., and Yang, Y. (2013). Cyclic testing of thin-walled circular steel tubular columns filled with demolished concrete blocks and fresh concrete. Thin-Walled Struct. 66, 50-61. doi:10.1016/j.tws.2013.01.008

Xiao, J., Huang, Y., Yang, J., and Zhang, C. (2012a). Mechanical properties of confined recycled aggregate concrete under axial compression. Construct. Build. Mater. 26 (1), 591-603. doi:10.1016/j.conbuildmat.2011.06.062

Xiao, J., Li, W., Fan, Y., and Huang, X. (2012b). An overview of study on recycled aggregate concrete in China (1996-2011). Construct. Build. Mater. 31 (6), 364-383. doi:10.1016/j.conbuildmat.2011.12.074

Xiao, J., Huang, Y., and Sun, Z. (2014). Seismic behavior of recycled aggregate concrete filled steel and glass fiber reinforced plastic tube columns. Adv. Struct. Eng. 17 (5), 693-707. doi:10.1260/1369-4332.17.5.693 
Yang, Y.-F. (2011). Behaviour of recycled aggregate concrete-filled steel tubular columns under long-term sustained loads. Adv. Struct. Eng. 14 (2), 189-206. doi:10.1260/1369-4332.14.2.189

Yang, Y.-F., and Han, L.-H. (2006a). Compressive and flexural behaviour of recycled aggregate concrete filled steel tubes (RACFST) under short-term loadings. Steel Compos. Struct. 6 (3), 257-284. doi:10.12989/scs.2006.6.3.257

Yang, Y.-F., and Han, L.-H. (2006b). Experimental behaviour of recycled aggregate concrete filled steel tubular columns. J. Constr. Steel Res. 62 (12), 1310-1324. doi:10.1016/j.jcsr.2006.02.010

Yang, Y. F., Han, L. H., and Wu, X. (2008). Concrete shrinkage and creep in recycled aggregate concrete-filled steel tubes. Adv. Struct. Eng. 11 (4), 383-396. doi:10.1260/136943308785836772

Yang, Y. F., Han, L. H., and Zhu, L. T. (2009). Experimental performance of recycled aggregate concrete-filled circular steel tubular columns subjected to cyclic flexural loadings. Adv. Struct. Eng. 12 (2), 83-194. doi:10.1260/ 136943309788251605

Yang, Y.-F., and Hou, C. (2015). Behaviour and design calculations of recycled aggregate concrete-filled steel tube (RACFST) members. Mag. Concr. Res. 67 (11), 611-620. doi:10.1680/macr.14.00204
Yang, Y.-F., Zhang, Z.-C., and Fu, F. (2015). Experimental and numerical study on square RACFST members under lateral impact loading. J. Constr. Steel Res. 111, 43-56. doi:10.1016/j.jcsr.2015.04.004

Yang, Y.-F., and Zhu, L.-T. (2009). Recycled aggregate concrete filled steel SHS beam-columns subjected to cyclic loading. Steel Compos. Struct. 9 (1), 19-38. doi:10.12989/scs.2009.9.1.019

Zhu, B. L. (1989). Seismic experiment of structure. Beijing, China: Earthquake Press [in Chinese, with English summary].

Conflict of Interest: The authors declare that the research was conducted in the absence of any commercial or financial relationships that could be construed as a potential conflict of interest.

Copyright (c) $2020 \mathrm{Xu}$, Chen and Zhou.. This is an open-access article distributed under the terms of the Creative Commons Attribution License (CC BY). The use, distribution or reproduction in other forums is permitted, provided the original author(s) and the copyright owner(s) are credited and that the original publication in this journal is cited, in accordance with accepted academic practice. No use, distribution or reproduction is permitted which does not comply with these terms. 


\section{NOMENCLATURE}

$\gamma$ RCA replacement percentage

$\nu_{\mathrm{s}}$ Poisson's ratio of steel

$\lambda$ slenderness ratio, $\lambda=4 L_{0} / D$

$\nu_{\mathrm{c}}$ Poisson's ratio of RC

$n$ axial compression level, $n=N / f_{\mathrm{c}} A_{\mathrm{c}}(1+\theta)$

$P_{\mathrm{y}}, \Delta_{\mathrm{y}}$ yield load and corresponding displacement, respectively

$\alpha$ shaped steel ratio, $\alpha=A_{\mathrm{s}} / A_{\mathrm{c}}$

$P, \Delta$ lateral load and corresponding displacement, respectively

$N$ axial loads

“ $\square$ " yield point

$f_{\text {ck }}$ measured axial compression strength of $\mathrm{RC}$

“ $\bigcirc$ " peak point

$A_{\mathrm{c}}$ cross sectional area of core RC column

" $\triangle$ " failure point

$A_{\mathrm{s}}$ cross sectional area of steel tube

$\mu$ displacement ductility coefficient, $\mu=\Delta_{\mathrm{u}} / \Delta_{\mathrm{y}}$

$\theta$ confinement coefficient, $\theta=A_{\mathrm{s}} f_{\mathrm{yk}} / A_{\mathrm{c}} f_{\mathrm{ck}}$

$P_{\mathrm{u}}, \Delta_{\mathrm{u}}$ ultimate load and corresponding displacement, $P_{\mathrm{u}}=0.85 P_{\mathrm{m}}$ $f_{\mathrm{yk}}$ measured yield strength of steel respectively

$L_{0}$ calculated length, off for $L$

$P_{\mathrm{m}}, \Delta_{\mathrm{m}}$ peak load and corresponding displacement

$D$ exterior diameter of steel tube

$h_{\mathrm{e}}$ equivalent viscous damping coefficient

$f_{\mathrm{y}}$ yield strength of steel

$K_{\mathrm{i}}$ secant stiffness

$f_{\mathrm{u}}$ ultimate strength of steel

$K_{\mathrm{j} 1}$ secant stiffness of displacement at various levels

$E_{\mathrm{s}}$ modulus of elasticity of steel

$K_{\mathrm{e}}$ elastic stiffness

$E_{\mathrm{c}}$ modulus of elasticity of RC

$K_{\mathrm{y}}$ yield stiffness

$\mathcal{E}_{\mathrm{y}}$ yield strain of steel

$K_{\mathrm{m}}$ maximum stiffness

$f_{\text {cu }}$ cube compression strength

$K_{\mathrm{u}}$ failure stiffness

$f_{\mathrm{c}}$ axial compression strength of RC

$\mu_{a}$ average value of displacement ductility coefficient 